\title{
WHAT IS THE BEARING OF THINKING ON DOING?
}

\author{
Marshall Bierson and John Schwenkler
}

Imagine that, while looking out of my front window, I see you surreptitiously remove mail from my neighbour's mailbox. What have I witnessed? I may have seen you stealing my neighbour's mail. But then again, I may instead have seen you do a favour for my neighbour by collecting her mail while she is away on vacation. This description of what I saw is indeterminate between whether you were stealing the mail or collecting it for safekeeping. Certainly, the description gives clues to which of these things was happening — for instance, the surreptitiousness of your behaviour is plausibly suggestive of theft. Yet while theft is often furtive, it is not the stealth that determines whether taking something amounts to stealing it. After all, there are suave thieves who don't bother to hide their behaviour, just as there are clandestine saints who are concerned only for their treasure in heaven.

The way to eliminate the ambiguity in our story is to add more information to it. For example, if we add to the description above that (1) my neighbour asked you to collect the mail and (2) you intend to give all the mail back to the neighbour when she returns from vacation, then the story did not involve stealing. By contrast, if instead of (2) we added that (3) you picked up the mail intending to keep whatever looks interesting, passing off the remainder as the complete collection, then our story may involve an act of theft.

Yet clearly I did not witness any of these further facts while looking out of my window and watching you take my neighbour's mail. I was not there when my neighbour asked you to pick the mail up for her, and I certainly did not see the intention with which you collected it. Nor could I see any number of the other facts that are relevant to the description of what you did. I 
could not peer through the outer mailbox and into the true normative relations that hold between the letters and their proper owner, or glance into your mind to see whether or not you mistakenly thought the mail your own. Yet each of these unobserved facts bears on the correct classification of your act.

This sort of indeterminacy is suggestive to philosophers. The description of what I saw, while accurate as far as it goes, fails to determine whether or not what I saw was an act of theft. Therefore, one might conclude, what I really saw must not have been you stealing the mail or taking it for safekeeping, but only a bunch of physical happenings. ${ }^{1}$ What happened 'out in the world' was just that you moved the mail out of the mailbox and into your house (or, perhaps, that the movement of a medium sized collection of atoms caused a tiny collection of atoms to move from one place to another). ${ }^{2}$ The theft, if it occurred, was not itself a worldly, physical process. An act of theft is somehow composite - it consists in the combination of physical, observable, worldly facts and certain further mental and normative ones.

What we can say about theft, we can say about the majority of our ways of describing human action. What happens 'out in the world' when someone intentionally launches down a slip-n-slide might be in many essential respects the same as what happens 'out in the world' when someone trips and skids: so intentional launchings are not purely physical, observable, worldly events, but causal compounds of physical events and their mental antecedents and

\footnotetext{
${ }^{1}$ The label 'Cartesian' is overused, but in the present case it is clearly appropriate: '... if I look out of the window and see men crossing the square, as I just happen to have done, I normally say that I see the men themselves, just as I say that I see the wax. Yet do I see any more than hats and coats which could conceal automatons? I judge that they are men. And so something which I thought I was seeing with my eyes is in fact grasped solely by the faculty of judgement which is in my mind.' (René Descartes, 'Second Meditation', in Meditations on First Philosophy: With Selections from the Objections and Replies, trans. John Cottingham (Cambridge: Cambridge University Press, 1996) p. 21. Our focus in this chapter is not on issues in the philosophy of perception, but for dissenting views see Jennifer Hornsby, Simple Mindedness (Cambridge: Harvard University Press, 2001) and Grace Helton, 'Visually Perceiving the Intentions of Other',' The Philosophical Quarterly 68 (2018), 243-264.

${ }^{2}$ We consider what is at stake in deciding between these two forms of description in Part II of our chapter.
} 
accompaniments. If the on-duty pilot and I are both asleep in our cabins, then we are doing the very same thing when our ship hits an iceberg. Yet it was the pilot, and not I, who sunk the ship: so sinking the ship was not a purely physical event, but a compound of what actually happened and some social and normative facts pertaining to the pilot's social role and consequent responsibilities. You and I could both sign the same form, and yet, because you were deceived about its content, only one of us may consent to undergoing an operation. Therefore, consent is not an act that happens 'in the world', by uttering certain sounds or making certain marks, but a compound of such bodily movements and an understanding of what they amount to.

Central to Elizabeth Anscombe's work in the philosophy of action is a rejection of this style of reasoning and the view of bodily action that it is taken to support. According to Anscombe, it is 'absurd to say that "A and B got married" ... and similar propositions, are not reports of physical facts, of physical (historical) events, things that have taken place in the overt, public history of the world. ${ }^{3}$ This is not to deny that there is a difference between a theft and a favor, a marriage and a mere rehearsal. Anscombe's claim is that these differences are not a matter of what obtains in some separate mental and normative realms, but are differences in what happens when the relevant things are done. Despite this, a witness to an action could be mistaken about what she actually sees. I might think I'm witnessing a beach wedding when I'm actually watching a peculiar flash mob. Nevertheless I am witnessing one or the other, a marriage or a mob. That which is there in the overt world, present before my eyes, is more than a bunch of bodily movements.

${ }^{3}$ G.E.M. Anscombe, 'On Promising and its Justice, and whether it need be respected in foro interno' (1969), repr. in Collected Philosophical Papers, Volume III: Ethics, Religion, and Politics (Oxford: Basil Blackwell, 1981), p. 11. 
A consequence of this position is that the correct description of physical facts, i.e. facts about what happens in the world, sometimes depends on such things as what a person thinks, what a person has been told, or the particularities of custom and positive law pertaining to things such as marriage and theft. For Anscombe, articulating the nature of this dependency is one of the central tasks of philosophical psychology. It is by this special dependency that actions, as described by biologists, anthropologists, and philosophers, are marked off from mere events, as studied by chemists and physicists. This dependency is also important for clarifying issues in ethical theory. There are, of course, important ethical differences between a deliberate murder and a botched appendectomy, or between mortally sinful adultery and good faith misunderstandign of one's marital status. It is therefore unsurprising that Anscombe, in the years between the first edition of Intention (1957) and the appearance of 'On Promising and Its Justice' (1969), was preoccupied with articulating the way that the nature of an action can depend on normative, social, and psychological facts.

First in Intention, later in 'Pretending' (1958), 'On Brute Facts' (1958), 'Modern Moral Philosophy' (1958), 'On Being in Good Faith' (late 1950s or early 1960s), ‘On Authority in Morals' (1962), and 'The Two Kinds of Error in Action' (1963), and finally in 'On Promising and Its Justice', Anscombe works to systematise the various ways in which facts about the wider context of an action make a difference to the true description of what a person does. In addition to her published work, this question was also a central preoccupation of many of the handwritten notes and unpublished (and unfortunately undated) drafts contained in the archive of her papers held by the Collegium Institute at the University of Pennsylvania. By looking at this body of work holistically, we can discern the central theoretical commitments in Anscombe's understanding of what we will call the bearing of thinking on doing. 
The remainder of this chapter will survey a decade of Anscombe's often seemingly idiosyncratic insights and examples, and translate them into a systematic overview of her position. We proceed in three steps. Part I distinguishes two ways that the description of an action can depend on its wider context, which we call circumstantial and classificatory dependency. The subsequent sections relate these two types of dependency to the question of how thinking bears on doing. Part II considers several ways that the description of what an agent does can depend on what the agent in fact thinks, and Part III how this can depend as well on what the agent should have thought, even if in fact she did not.

\section{Circumstance and Classification}

In her early paper 'On Brute Facts', Anscombe illustrates the distinction between circumstantial and classificatory dependency with the example of owing a grocer money for potatoes. ${ }^{4}$ If someone asks me, 'Why do you owe the grocer four pounds?' I might answer by citing facts like 'He delivered me the two kilograms of potatoes that I had ordered last Tuesday', and 'The potatoes cost 4 pounds'. Anscombe contrasts 'these facts' about what transpired with what she calls institutional facts, such as the fact that in our social institutions such a pattern of exchange results in my having a financial debt. It is certainly true that, had these institutional facts been different, the same first-order facts could have obtained without my owing the grocer anything at all. For we could imagine very different property norms according to which the same 'facts on the ground' would not entail that I owe the grocer any money: for instance, those that would govern the exchange of goods in a society in which, because food is necessary for survival, all

\footnotetext{
${ }^{4}$ G. E. M. Anscombe, 'On Brute Facts' (1958), repr. in Collected Philosophical Papers, Volume III:
} Ethics, Religion, and Politics, (Oxford: Basil Blackwell, 1981), 22-25; at pp. 23-24. (Also compare Anscombe, 'Modern Moral Philosophy' (1958), repr. in Collected Philosophical Papers, Volume III: Ethics, Religion, and Politics (Oxford: Basil Blackwell, 1981), 26-42; at p. 28.) 
food prices are merely suggested donations; or in a highly legalistic society where the fact that the grocer did not have the bill notarised voided the contract. Anscombe argues, however, that there is a difference between the way my owing money to the grocer depends on the facts of the exchange and the way this debt depends on the social institutions in which this exchange takes place. Here is how she introduces the latter form of dependency, which is the one we will call classificatory:

Does my owing the grocer in this case consist in any facts beyond the ones just mentioned [viz., that I asked for the potatoes and the grocer delivered them and sent me a bill]? No. Someone may want to say: it consists in these facts in the context of our institutions. This is correct in a way. But we must be careful, so to speak, to bracket that analysis correctly. That is, we must say, not: It consists in these-facts-holding-in-thecontext-of-our-institutions, but: It consists in these facts - in the context of our institutions, or: In the context of our institutions it consists in these facts. For the statement that I owe the grocer does not contain a description of our institutions, any more than the statement that I gave someone a shilling contains a description of the institution of money and of the currency of this country. ${ }^{5}$

While it is helpful to employ a formalism in order to help keep track of these distinctions, Anscombe's way of doing this is a bit unwieldy, and so we will represent these classificatory dependencies as functions instead. On a first pass, a classificatory dependency can be represented with a function that takes certain inputs, e.g., that I asked the grocer for the potatoes

\footnotetext{
5 'On Brute Facts', p. 22
} 
and he delivered them to me and sent me a bill, and returns from them an output, e.g., that I owe the grocer four pounds. Applied to the present case, the function would be as follows:

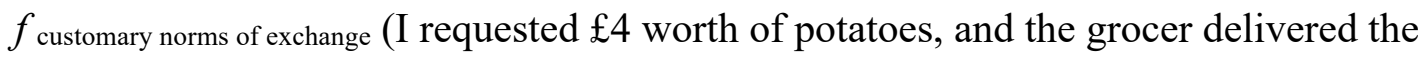
appropriate quantity and sent me a bill) $=$ I owe the grocer four pounds

The purpose of this apparatus is to help us keep separate the roles played by what we have so far identified as the 'facts on the ground', i.e. those that concern what happens in the course of events, which are represented here as inputs to the function $f_{\text {customary norms of exchange, }}$ and the classificatory functions themselves, in virtue of which those inputs result in something furtherin the present case, that I owe the grocer a certain sum of money. In the context of different institutions, such as one in which the bill from the grocer was void unless I signed it upon receipt, these same things could have happened without my thereby owing four pounds to the grocer. The description of what happens does not include a description of the institutions within which it takes place, though it is only against the background of those institutions that it amounts to a description of my coming to owe money to the grocer.

We can distinguish, then, two kinds of dependency. There is circumstantial dependency, illustrated here in the way that my owing the grocer depends on the grocer having delivered the potatoes, and so on, and classificatory dependency, illustrated here in the way that our customary norms classify these circumstances as an exchange which results in my owing money to the grocer. However, it is not only local customs and institutional norms that provide a wider context within which certain happenings may result or fail to result in something further. Here is another 
of Anscombe's examples of circumstantial dependency, from the paragraph following the one just quoted:

Given this background [viz., that of our customary norms of exchange], these facts [viz., that I asked for the potatoes and the grocer delivered them, etc.] do not necessarily amount to my owing the grocer such-and-such a sum. For the transaction might have been arranged as part of an amateur film production. Then perhaps I have said to the grocer 'Send so many potatoes' and he has sent them, and he has sent a bill - but the whole procedure was not a real sale but a piece of acting; even though it so happens that I then eat the potatoes (not as part of the film): for perhaps the grocer has said I can keep them; or has said nothing but doesn't care, and the question never comes up. Thus the fact that something is done in a society with certain institutions, in the context of which it ordinarily amounts to such-and-such a transaction, is not absolute proof that such-andsuch a transaction has taken place. ${ }^{6}$

There are two lessons to draw from this case. One, which we will discuss at more length below, is that the logic of a classificatory function will usually not be such as to entail that its output obtains, given that its inputs do: for there will be an indefinite number of possible special circumstances, the obtaining of which would keep this entailment from going through. Second, notice that the 'context' that Anscombe discusses in this quotation plays a different role in determining what results from certain happenings than do the institutional norms discussed above: for here we have a case in which both those happenings and the surrounding norms of

\footnotetext{
6 ‘On Brute Facts', p. 22.
} 
exchange are held constant, and nevertheless there is a difference in what comes about. Other cases have a similar structure: for example, there can be many different sets of house rules that determine what happens when a player lands on 'Free Parking' in a game of Monopoly, but in addition it is only if a person is playing Monopoly that her rolling a die and moving her piece the corresponding number of spaces to the square marked 'Free Parking' counts as her landing her piece on that square. This suggests that the inputs to a classificatory function will often make at least an implicit reference to the wider context of the events that they describe, in virtue of which the operative institutional norms then have application to them. Of course, in many cases the explicit description that can be given of the wider context of an action won't itself be very informative - indeed, it might say only that the context of what happened was the ordinary one. Nevertheless, that something was done in an ordinary context may be one of the circumstantial facts upon which further descriptions of her action depend.

Before we go on to generalise this machinery, it is important to clarify a few points. First, notice that where it is natural to distinguish what happened from the wider context in which it took place will sometimes depend on our particular explanatory interests, and the distinction will not always be perfectly sharp. For example, if Helen moves her piece six squares ahead on the Monopoly board in order to show her younger sister how to play, then because her move was merely illustrative she won't receive the consequences of the square that she landed on. Is the difference between this case and the one where Helen 'really' moves her piece a difference in what is done, or is it rather a difference in the wider context? One can imagine situations in which either answer would be acceptable, as well as others where it is hard to see what the point of the distinction would be. ${ }^{7}$ Similarly, in some situations the description we give of what

\footnotetext{
${ }^{7}$ Here it helps to compare what Anscombe says about reasons and causes in section 17 of Intention.
} 
happens might depend on the norms it was subject to: someone who lays down a certain card during a game of Bridge might be described as doing a different thing, say trumping, than someone who lays down the same card while playing Hearts. Second, let us reiterate that functions that pertain to the description of an action differ from mathematical functions in that the facts that are input to the function are not logically sufficient conditions for their output. As we have seen, Anscombe thinks that in many institutional contexts there are indefinitely many special circumstances that might block a given classificatory inference. For instance, if the exchange of potatoes from our earlier example occurred in a play, then one actor does not really owe the other any money. This will be true even if one of the actors really is a grocer and brought the prop-produce from their store. Nevertheless, when someone asks why I owe the grocer four pounds, we generally think there is no need to mention that the exchange did not occur as part of a play (and indeed, it would be impossible to list all the possible exceptions that might have kept the inference from going through).

Finally, we note that a helpful feature of our formalism is the way it makes it possible to represent how one classificatory dependency may be embedded within another. Consider, for example, the following two functions:

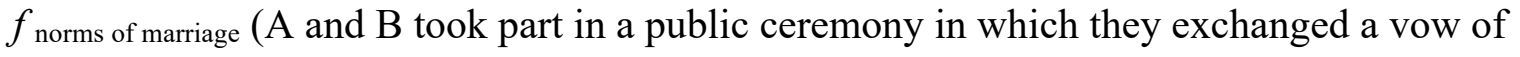
lifelong fidelity $)=\mathrm{A}$ and $\mathrm{B}$ are married

$f_{\text {moral law }}$ (A and B are married, and $\mathrm{A}$ had sexual intercourse with someone other than $\mathrm{B}$ ) $=$ A committed adultery 
These functions are related, as the first one identifies a condition that can be treated as an input to the second. However, it is helpful to represent them as separate functions since doing so allows us to distinguish the different sorts of mistakes a person may make in considering the proper description of what she does. For example, a person who thinks that two people who have publicly exchanged a vow of lifelong fidelity are no longer married if they have subsequently fallen out of love and lived apart from each other for a year may mistakenly think that she is not married to someone even though they exchanged vows in a marriage ceremony and have not formally divorced. Alternatively, a person might accept the above classification of marriage but think that that, as long as her spouse has consented to it, having intercourse with another person is not really an act of adultery. The first sort of person rejects the classification of marriage represented in our function $f_{\text {norms of marriage }}$, while the second rejects the classification of adultery represented in $f_{\text {moral law }}$. On Anscombe's view (and ours), both of these positions are mistaken, but it is not hard to imagine how someone could come to endorse them.

It is useful to have this conceptual background in place when we consider Anscombe's views about the bearing of thinking on doing, as the distinction between circumstantial and classificatory dependency is central to her account. Nevertheless, we have not yet uncovered Anscombe's most interesting insights. The real philosophical work comes in when we try to explain the way that the classification of what an agent does can depend in a circumstantial way on what the agent thinks or is responsible for thinking.

\section{Thought}

A central aim of Anscombe's Intention is to distinguish what she calls the special 'form of description' that we bring to bear in characterizing events as voluntary or intentional actions, 
from the quite different form that events are described in when there is no such reference to purposive agency. This contrast is marked initially in the distinction between two senses in which the question 'Why?' may ask for an explanation of what happens: ${ }^{8}$ on the one hand there is the use of 'Why?' to ask for someone's reasons for acting, i.e., the considerations suggesting that her action was something 'good to make happen with a view to an objective, or with a view to a sound objective'; ${ }^{\prime}$ and on the other there is the sense in which 'Why?' seeks to identify the causes of what takes place. The distinction reappears in different guises later in the book, first in Anscombe's discussion in Sections 20-27 of the 'A-D order' that represents how in an action means are taken to a further end, and later on in her account in Sections 33-44 of practical reasoning as the calculation of means to an end. Finally, it is toward the end of Intention that Anscombe articulates this distinction in terms of two different 'forms of description', one of which characterizes events simply as 'the movements of humans' ${ }^{10}$ and the various further 'things effected by' these movements, ${ }^{11}$ while the other is 'the description of what happens as a human action' ${ }^{12}$ or the kind of description we would give if our aim were to provide 'the history of a human being's day or life'. ${ }^{13}$ The two columns in her list of action words in Section 47 of Intention provide examples of the latter category: ${ }^{14}$ for in describing someone as, say, intruding on a private meeting, offending her coworker, kicking a stone, dropping her silverware, switching on or off a light, and placing down her bag or arranging papers on her desk; or again as telephoning her cousin, calling her daughter to breakfast, groping in the dark for her glasses,

\footnotetext{
${ }^{8}$ For this discussion see G. E. M. Anscombe, Intention, 2nd ed. (1963), repr. Cambridge: Harvard University Press (2000), §§6-18.

${ }^{9}$ Intention, p. 4.

${ }^{10}$ Intention, p. 83.

11 Intention, p. 85.

12 Intention, p. 83; emphasis added.

13 Intention, p. 85.

14 Intention, p. 85.
} 
signing a contract, paying for her lunch, and hiring a gardener or contracting to have her house painted, we are bringing her movements under concepts 'which go beyond physics' and 'are basically at least animal'. ${ }^{15}$

That descriptions of this sort are presented, in the first place, as 'vital descriptions' or descriptions of 'characteristically animal movements' ${ }^{16}$ rather than by emphasizing the way that special concepts like 'telephoning' or 'writing a sentence on the blackboard" ${ }^{17}$ make reference to specifically human capacities, institutions, and forms of life, is an important point to emphasize in the present context, as is the account Anscombe gives of what makes a movement 'characteristically animal': it is a movement 'with a normal role in the sensitive, and therefore appetitive, life of animals'. ${ }^{18}$ She gives several examples to illustrate the way that our descriptions of the movement of animals depends on the presence of sensation and appetite:

A dog's curled tail might have something stuck in it, but that of itself would not make us speak of the dog as holding the object with its tail; but if he has taken between his teeth and kept there some moderate-sized object, he is holding it. ${ }^{19}$

... we describe what [animals] do in a manner perfectly characteristic of the use of intention concepts: we describe what further they are doing in doing something (the latter description being more immediate, nearer to the merely physical): the cat is stalking the bird in crouching and slinking along with its eye fixed on the bird and its whiskers

\footnotetext{
15 Intention, p. 86.

${ }^{16}$ Intention, p. 86.

${ }^{17}$ Intention, p. 84.

${ }^{18}$ Intention, p. 86.

${ }^{19}$ Intention, p. 86.
} 
twitching. The enlarged description of what the cat is doing is not all that characterises it as an intention (for enlarged descriptions are possible of any event that has describable effects), but to this is added the cat's perception of the bird and what it does if it catches it. The two features, knowledge and enlarged description, are quite characteristic of description of intention in acting. Just as we naturally say, 'The cat thinks there is a mouse coming', so we also naturally ask: Why is the cat crouching and slinking like that? And give the answer: It's stalking that bird; see, its eye is fixed on it. We do this, though the cat can utter no thoughts, and cannot give expression to any knowledge of its action, or to any intentions either. ${ }^{20}$

The constitutive role of sensation and appetite is easiest to see in Anscombe's second case: for a cat is not described as stalking a bird if it merely happens to be crouching and slinking in the grass behind one (say as a trained trick), but only if it is doing this sort of thing because it sees the bird and wants to catch it. That is, it is only within such a wider context that an 'enlarged description' like stalking the bird can have application to the movements of a cat. But a similar point applies, at an even more fundamental level, to her case of the dog that holds an object in its mouth, as for this to happen is not just for the object to be held in the dog's mouth in the way that a rock may be held in a cleft, but rather for the dog to keep the object in its mouth because it knows the object is there and wants it to remain. A similar point applies in turn to the phrase 'taken between his teeth', as this description conveys something more than an object's simply having gotten stuck there. ${ }^{21}$ (That is why talk of wind or water as 'picking up', 'putting down',

${ }^{20}$ Intention, pp. 86-87.

${ }^{21}$ It applies as well to Anscombe's description of the cat as 'crouching' and 'slinking', as even these 'immediate' descriptions say more than just that the cat's body is moving around in certain ways- for they too are descriptions that 'go beyond physics'. 
'carrying', etc. is necessarily analogical: with inanimate forces there is no room to distinguish between, say, lifting something and merely happening to move in a way that causes the thing to rise.) In describing the movements of humans and other animals we consistently draw on words and phrases that 'are formally descriptions of executed intentions': ${ }^{22}$ these terms 'describe what further [an agent] is doing in doing something, ${ }^{23}$ and the applicability of these further descriptions depends on the agent's own perceptions and desires, as well as on assumptions about what the agent will do if a certain desire is or is not fulfilled.

It would be a mistake to conclude from this that in describing a cat as stalking a bird, or a dog as holding something in its teeth, we are postulating some psychological states that accompany the animal's observable behaviour in a way that renders the latter voluntary or intentional under certain descriptions. This is a point that Anscombe makes early on in Intention, when she has us imagine walking in to her room to find her 'sitting in a chair writing': ${ }^{24}$ Anscombe says that such a description will 'in general' be the 'first account' a person would give 'of what [she] was doing ${ }^{25}$ - and to give such an account is to give an account of something that is happening in the room one enters. Yet the description of a person as writing, rather than of, say, 'how [she] was affecting the acoustic properties of the room', ${ }^{26}$ is not a description to which there corresponds 'a picked-out set of movements ${ }^{27}$ of a sort we have found that writing usually involves. Rather, the best way we have to describe the bodily movements that writing involves is to say that they are the sort of movements involved: in writing. And we would have

\footnotetext{
22 Intention, p. 87.

23 Intention, p. 87.

${ }^{24}$ Intention, p. 8.

${ }^{25}$ Intention, p. 8.

${ }^{26}$ Intention, p. 8.

${ }^{27}$ Intention, p. 83.
} 
no interest in picking out movements of this sort if not for the role that they usually play in this special form of self-conscious expression. Moreover, as we have seen, even the 'immediate' description of a person as holding a pen or moving her hand around already draws on concepts of characteristically animal movement whose applicability presupposes the presence of perception and desire. There is no 'fundamental description[...] of what occurs - such as the movements of muscles or molecules' which when suitably accompanied by certain psychological states make for an event of someone's writing: rather, in describing someone's actions '[t]he only events to consider are intentional actions themselves' ${ }^{28}$

We should notice, however, that there is an important difference between the way that an animal's 'knowledge of its own action' ${ }^{29}$ bears on the applicability of descriptions like 'kicking', 'dropping', 'holding', and 'stalking', and the further kind of self-knowledge that is presupposed by descriptions like 'building a house' or 'writing a sentence on a blackboard' ${ }^{30}$ In 'The Two Kinds of Error in Action', Anscombe illustrates the latter sort of dependency with the example of consenting to a contract: 'Consent', she writes, 'is consent to something', and that which is consented to must be apprehended by the person who consents to it. ${ }^{31}$ But this intellectual apprehension is different from the kind of apprehension involved in picking something up or holding it in one's mouth: for while the verbs 'pick up' and 'hold' necessarily take a direct object, and so picking up and holding are necessarily picking up and holding something which the agent must perceive and desire to possess, the descriptions under which a person represents an object that she picks up or holds is irrelevant to the descriptions we may give of her as doing

28 Intention, p. 29.

${ }^{29}$ Intention, p. 87.

${ }^{30}$ Intention, p. 84.

${ }^{31}$ G. E. M. Anscombe, 'The Two Kinds of Error in Action' (1963), repr. in in Collected Philosophical Papers, Volume III: Ethics, Religion, and Politics (Oxford: Basil Blackwell, 1981), 3-9; at p. 3. 
this. ${ }^{32}$ By contrast, at least in the usual case a person writing a sentence must know what sentence she is writing, a person building a house must know what it is that she is building, and a person consenting to a contrast must know what it is that she is consenting to. The applicability of these descriptions depends on the agent herself bringing her action under them.

Three important points require clarification. First, it is possible for there to be cases in which a person unwittingly writes a given sentence or participates in the building of a house, say because she is following orders or instructions whose purpose she doesn't understand. Notice, however, that in such a case the description of the agent as doing the relevant thing depends on the presence of that description in the order or instruction that the agent follows: thus someone writing down symbols that are being fed to her randomly is not thereby writing whatever sentence those symbols may eventually happen to form. Second, it is possible to say that an agent has done a thing of this second sort even if she has done it unwittingly, as for example a monkey might produce a Shakespearean sonnet by pushing keys on a typewriter. However, the description of a person as presently doing such a thing does not depend on what she has already done, nor on what she is eventually going to do: for a person may be writing a certain thing, say the word 'intention', at least as soon as she has made the first mark, and even if lightning strikes before she gets to the end. ${ }^{33}$ The applicability of this wider description depends on the agent's own understanding of what she is up to, or on the content of the instruction or order she is following. Finally, we wish to emphasize that the distinction that interests us here is not simply a

\footnotetext{
32 In her archival notes Anscombe puts the point like this: 'we can only define this class; actions via intention. Intention (in what happens) implies agency, however lack of intention doesn't imply non-agency. If I spill coffee thinking it tea I don't spill coffee intentionally. This means: a man is the agent of an act if what he does can be described under an aspect that makes it intentional' (Archive, Box F5, File 509, p. 121).

33 This has been helpfully emphasized by Michael Thompson: see his Life and Action (Cambridge: Harvard University Press, 2008), Part II; and 'Anscombe's Intention and Practical Knowledge', in A. Ford, J. Hornsby, and F. Stoutland, eds., Essays on Anscombe’s Intention (Cambridge: Harvard University Press, 2010), 198-210.
} 
matter of cognitive sophistication: for just as our remarks about concepts like 'picking up' and 'holding' apply equally well to rational agents, and so to describe, for example, a bird as building a nest or a beaver a dam may presuppose that this animal has, not necessarily 'in mind' but as something that informs what it does, an understanding of what the finished product will be like. ${ }^{34}$ The two kinds of dependency we have just discussed can be represented using the formalism introduced in Part I. First, in the case of concepts of animal movement like 'walk', 'stalk', 'pick up', and 'hold', our suggestion is that among the circumstantial facts that these classifications depend on are facts about the acting animal's thoughts, perceptions, and desires. For example, the description 'A stalks B' is not sufficiently represented just with the function $f$ folk zoology (A moves quietly in a path that follows the path of B), but requires further that A does this because it perceives B and wants to catch it. (This is not to deny that we can use the word 'stalk' to describe what happens in the absence of these further circumstances- - the point is rather that our ordinary use of the word makes implicit appeal to a wider context.) Second, in the case of special concepts like 'consent', 'write', and 'marry', the circumstantial facts that these classifications depend on include the agent's knowledge of the classificatory fact itself: thus the function $f_{\text {norms of marriage }}$ that we introduced in Part $\mathrm{I}$ is in fact incomplete, as it is missing the crucial circumstance that in exchanging this vow A and B knew that they were thereby getting married. If instead A thought that the ceremony he was participating in was only a rehearsal, or that the vows they were taking didn't hold any official status, such that they could be dissolved

\footnotetext{
34 This point is a bit tricky. For example, a bird could build a nest just by executing an internal 'program' that has it pick up one piece of material after another and arrange them in the appropriate manner. That the bird stops when the nest is done doesn't require it to have had any representation of what a finished nest would look like. The remarks above are meant to mark a possibility rather than put it forward as the appropriate description of what actually happens.
} 
in the future just by deciding to go their own ways, then A and B will not have gotten married at all.

This last point needs to be handled with care. First, note that we are not treating the knowledge that one is doing $\mathrm{X}$ (getting married, say, or signing a contract) as a matter of applying the word ' $\mathrm{X}$ ' to what one is doing: for people can get married who do not speak English, or even in cultures that do not have any special word for this institution. ${ }^{35}$ (This point will not apply to descriptions like 'writing such-and-such a word', for obvious reasons.) Rather, in cases like these the essential thing is that the agent has an understanding of the normative upshot of what she does: thus a person getting married will have to understand the obligations that come with marriage, the permanence of this institution, and its status as a civic institution rather than a mere personal pact; a person signing a contract will have to understand her obligation to do what the contract describes; and so on. Second, as this characterization suggests the knowledge that these actions depend on may come in degrees, and sometimes there will be borderline cases where it is hard to say whether or not a person knew enough of what she was doing to count as doing such-and-such. Finally, we grant that in practice the mere fact that, for example, a person who took part in a marriage ceremony failed to understand the permanence or civic status of marriage might not be a sufficient reason to regard their marriage as null and void — though it would be good grounds for subsequent annulment or divorce. Similarly, a person who writes in an email message that she'll do something may in practice be treated as

\footnotetext{
${ }^{35}$ However, we find it difficult to see how there could be a workable set of customs in which knowledge of what one was doing was not a requirement of getting married. One thing to bear in mind here is that we are talking specifically about ceremonial marriage, as opposed to the way people may become married as a matter of common law, say by having lived together for such-and-such a time. And it seems essential to the very idea of a marriage ceremony that it involve a contract, promise, or other expression of commitment to the person one is marrying. As we discuss below, however, there is a strong case that promising is essentially something a person cannot do without knowing that she is doing this.
} 
having contracted to do this even if she didn't understand that her emailed statement was binding. However, this does not show that actions like these do not depend on knowledge of what one is doing. The reason for these practices is rather that a person's claim not to have known something is defeasible — she could be lying or misremembering. Because of this, the claim 'I didn't know' cannot always be treated as sufficient to dissolve one's obligations even when what one says would, if true, suffice to show them illusory.

An important consequence of this account is that the force of a claim not to have known what one was doing will differ depending on what kind of action one was engaged in. Where mere concepts of animal movement are concerned, the claim 'I did not know I was doing that!' functions, as Anscombe observes in Intention, ${ }^{36}$ as a way of saying that one did not do the thing in question intentionally or on purpose, even if one may in fact have done it. For Anscombe, the case of adultery falls in this category as well on her analysis: the fact that X did not know that $\mathrm{Y}$ was not his spouse does not show that $\mathrm{X}$ did not commit adultery in having intercourse with $\mathrm{Y}$, though in most cases it will be enough to show that he was not responsible for doing this. (We will consider this concept of 'responsibility' shortly.) In 'The Two Kinds of Error in Action' she uses Thomas Aquinas' language of 'formal' and 'material' objects to explain this contrast: if X believes that $\mathrm{Y}$ is his spouse but in fact she is not, then $\mathrm{X}$ commits adultery materially but not formally, just as a hunter who mistakes his father for a stag aims formally at a stag but materially at his father. ${ }^{37}$ By contrast, Anscombe observes that the claim that one did not know she was

${ }^{36}$ Intention, pp. 11-12.

37 'The Two Kinds of Error in Action', p. 5. The case of a man shooting his father is due to St. Thomas Aquinas: see Summa Theologiae, IaIIae, q. 6, a. 8, c. For the language of formal vs. material objects of will, see $S T$ IaIIae, q. 18, a. 6, c. (We thank Daniel De Haan for the latter reference.) In the present context, the language of what is done formally, or of the formal object of knowledge or the will, is equivalent to that of intentional action and intentional object. For related discussion see Jennifery Frey and Christopher Frey's important paper, 'G.E.M. Anscombe on the Analogical Unity of Intention in Perception and Action', Analytic Philosophy 58 (2017), 202-247. 
participating in a real marriage ceremony rather than a rehearsal, or signing a contract that committed her to do X, is a way of saying that one did not do the thing in question at all (not even 'materially' or by accident), since without this knowledge an act of the relevant sort simply cannot have taken place. ${ }^{38}$ And she argues as well that there is a third category other than these two, in which the description of an agent as doing something depends on her knowledge of what she is doing, though not under the very description in question. She illustrates this category with the examples of theft and murder, which she argues 'are so used that formality is essential to them; it is built into their meaning'. ${ }^{39}$ Yet the way that formality is essential to these concepts is different from the way it is essential to those of marriage and promising, as it concerns knowledge of the circumstances of one's action rather than of the appropriate classification of them. For example, she writes that what makes us say a person did not steal in taking someone else's property is that the person 'genuinely and reasonably, but wrongly, thought that this was property he had a right to take away ${ }^{40}$ _ as, for example, when a traveler at the airport mistakes someone else's suitcase for her own. A similar point holds in the case of murder:

You have to think you are making a contract in order to be doing so, whereas you do not have to think that what you do is murder in order for it to be murder. What is necessary for your action to be murder is that you deliberately do such-and-such; this entails that you know you are doing such-and-such. ${ }^{41}$

${ }^{38}$ Of course a person can marry someone, $X$, not knowing that $X$ falls under a further description ('a pauper', say). In such a case we might say that the person married a pauper unintentionally. But still it presupposes ('de re') knowledge of marrying X.

39 'The Two Kinds of Error in Action', p. 5.

40 'The Two Kinds of Error in Action', p. 5.

41 'The Two Kinds of Error in Action', p. 5. 
The distinction that Anscombe is drawing here can be represented using our formalism. One of the circumstantial inputs necessary for the function $f_{\text {norms of marriage }}$ to classify $\mathrm{A}$ and $\mathrm{B}$ as getting married is that A and B bring what they are doing under the very concept that this function represents. By contrast, the corresponding circumstantial input necessary for the function $f_{\text {moral }}$ law to classify A as murdering someone is that A knows that what she is doing falls under the other descriptions that this function takes as input: most obviously, A must know that she is killing an innocent person. According to this analysis, a person can murder someone even if she thinks, perhaps because the act is committed in the context of a war, that to act in this way is not really to commit an act of murder at all. Similarly, the definition of theft requires that the agent know that she is taking as her possession something that belongs to another person, but not that she know that, in doing this, she is stealing.

This brings us back to the brink of a pressing philosophical question. It seems clear why descriptions like 'marrying' and 'contracting' should include an agent's knowledge of her doing the thing in question as one of their conditions of application: this is because those words describe communicative acts through which a person takes on some special obligations, not as a mere consequence of what she does (as when a person who damages another's property has the responsibility of making restitution), but in virtue of a social practice that allows us to obtain certain goods by restricting their possibilities for future behaviour. ${ }^{42}$ Because of this, we cannot understand how a person who signs a contract or makes a promise, etc., is thereby committed to doing the further things she contracts or promises to do except by seeing the original act as one of self-consciously committing herself to do these further things. ${ }^{43}$ And the relevance of self-

\footnotetext{
42 The foregoing is a very compressed summary of Anscombe's analysis of promising in 'On Promising and its Justice'.

${ }^{43}$ Some tricky issues arise here. A person who signs a contract carelessly, without knowing what she is doing, might have an obligation to have the contract officially voided, or even an obligation to do the very thing that
} 
knowledge to the concepts of murder and theft is different from this: in those cases, an agent's knowledge of her action bears on the proper way of holding her accountable, through practices of praise and blame, reward and punishment, for doing something, such as killing someone or taking another's property, which she could also have done in ignorance. But then why should it be that a person's knowledge of the circumstances of these acts is a presupposition of holding him or her accountable for them?

\section{Responsibility}

Certain human actions, like promising, depend on full knowledge of the nature of one's act. Others, like theft, require at least partial knowledge of one's movements and their wider circumstances. These dependencies, however, suggest a troubling moral strategy. To steal is to do a terrible thing; similarly, to renege on a promise is to open oneself up for certain censure and blame. Therefore, if one can cultivate a special ignorance, say about others' ownership of objects you want and about the classificatory conditions of promising, then one can ensure that she never steals or reneges on a promise. Similarly, while one way to avoid sin in war is to carefully adopt policies that discriminate between combatants and the innocent, how much easier it would be to refrain from ever inquiring into the possible civilian status of your targets, thus insulating yourself from the charge of knowledgeably killing the innocent! It thus appears that on Anscombe's own account 'sufficient thoughtlessness is a safeguard against committing mortal

it describes. But that is not because, in signing the contract, she committed herself to any of this. Rather, to use some terminology that we introduce just below, it is because a person who signs a contract is taken to be responsible for knowing what it is that she is doing, and so can be held to account for the consequences of her carelessness. In a similar way, someone who carelessly makes a statement that is subject to obvious misinterpretation can be held to account for misleading her audience even if she didn't lie in what she said. 
$\sin { }^{44}$ And this conclusion would be absurd. The military general cannot avoid legitimate moral condemnation by maintaining a carefully curated ignorance. Instead, she must do all she can to minimise civilian casualties.

We can put the general problem as follows. Terms like 'guilty', 'sinful', 'blameworthy', 'praiseworthy', 'meritorious', and so on express concepts that have application only to the actions of human beings and other rational agents, and not to things done by hurricanes, turtles, boulders, and the like. But haven't we just seen that in general those descriptions endemic to rational agents are ones which circumstantially depend on the knowledge of what one does? A boulder and I can both tumble down a cliff. A dandelion and I can both grow taller. A dog and I can both chase a squirrel. Yet only you and I can write, promise, murder, or marry. The reason why only we are capable of the latter is because acts of this sort depend circumstantially on a kind of knowledge that is available only to rational creatures. This suggests that, if it is a form of self-knowledge that allows for actions to be classified as 'sinful', 'blameworthy', and so on, then the inculcation of strategic ignorance should be a way to insulate oneself from them.

\section{Voluntariness}

The first step toward addressing this worry is to identify the common element among our various ways of describing someone's behaviour so as to identify them as an appropriate target of praise or blame. A first step toward doing this is to note the different forms of excuse that we take to show a person not to have sinned, or not to have acted in a manner deserving of blame. For example, I cannot be blamed for ruining your cake if I had no way to know that you kept your salt in sugar bags and sugar in salt shakers. On the other hand, I can be blamed for missing your

\footnotetext{
44 'On Being in Good Faith', in M. Geach and L. Gormally, eds., Faith in a Hard Ground: Essays on Religion, Philosophy and Ethics by G. E. M. Anscombe (Exeter: Imprint Academic, 2008), 101-112; at. p. 101.
} 
piano recital if I was dragged away by a group of ruffians, just so long as I had paid those ruffians to drag me to the movies so that I'd have an excuse to skip the recital. ${ }^{45}$ For Anscombe, what explains this pattern is that notions like sin and blame do not require us to attribute the action to a person simply qua physical body (something that we can do in the first case and not in the second), but rather to their rational will. ${ }^{46}$ It is attributing an action to the will that grounds the application of concepts like guilt and sin. In her early manuscript, 'On Being in Good Faith', Anscombe introduces the term voluntary as a shorthand for what makes an action subject to this form of attribution. ${ }^{47}$ As Anscombe uses this term, to 'ascribe to the will and to call voluntary are the same' ${ }^{48}$

Importantly, this use of the word 'voluntary' differs from the use according to which the voluntariness of an action is incompatible with its having been coerced or performed under

${ }^{45}$ For the latter case see G.E.M. Anscombe 'Sin: the McGivney Lectures', in Geach and Gormally, eds., Faith in a Hard Ground: Essays on Religion, Philosophy and Ethics by G. E. M. Anscombe (Exeter: Imprint Academic, 2008), 117-156; at p. 129.

${ }^{46}$ In her archival materials Anscombe ties this idea of a rational agent to a condition of "callability to account' (Archive, 6, File 209, pp. 25-27). On her view, only rational agents can 'give an answer or account' for what they did, and so only they can be subject to this special type of responsibility.

${ }^{47}$ Anscombe's use of the word 'voluntary' changes somewhat during the period we are exploring. In Intention, she uses the contrast between the 'voluntary' and 'involuntary' first to mark the difference between 'purely physical' bodily movements like peristalsis or a reflex kick (Intention, pp. 14-15; and cf. pp. 23-24 and 3233 ), and later on the voluntary is contrasted with the intentional according to $(a)$ whether movements are absentminded or 'considered by the agent' (p. 89) and (b) whether the agent's doing something is either a 'known concomitant result of [their] intentional action' or something the agent does not do but which 'happens to their delight' (ibid.). Finally, Anscombe acknowledges that we sometimes use 'involuntary' to describe things that a person 'regrets "having" to do', though she adds that "'reluctant" would be the more commonly used word' (p. 90). By contrast, in her writings from the early 60 s Anscombe continues to see the voluntary as broader than the intentional, but now ties the concept far more explicitly to concepts like sin, responsibility and blame (see, e.g., 'On Being in Good Faith', p. 105). Anscombe's later writings, e.g. in her McGivney lectures, largely follow the latter treatment, but with some important refinements.

48 'On Being in Good Faith', p. 110. In one of her archival files Anscombe gives an extended articulation of this definition by using 'free' as an intermediary concept. She writes: 'voluntary behaviour is behaviour in respect of which the behaver is free. To be free is to be in a situation of possibility of determining something to accord with one's will' (Archive, Box 9, File 304, p. 1). She goes to tie this notion of 'will' to humans, writing that 'if we speak of desire instead of will here we erect a modified or half-way concept of freedom which we can apply to animals other than the human kind' (ibid.). 
duress. ${ }^{49}$ In her 1989 McGivney lectures, Anscombe is explicit that in her writings the word 'voluntary' is 'being used in a specially broad way' such that 'we do not say that acts done under threat are not voluntary'. ${ }^{50}$ Similarly, in one of her unpublished manuscripts Anscombe explicitly distinguishes her notion of the voluntary from the notion that Aristotle appeals to in saying that a ship's crew who throws cargo overboard during a storm in order to lessen the weight of the ship will do this only involuntarily. ${ }^{51}$

For now, let's stipulate the definition of voluntary as that which can be attributed to the will in a way that holds the agent responsible, and set aside the question of whether the term should be defined in this way. For we can accept this stipulated definition without agreeing with Anscombe that actions done under duress are not voluntary. That is because one could defend the substantive philosophical position that agents are not responsible for what they do under threat. Perhaps the fact that one was acting under threat is sufficient to block attribution to a person's will. ${ }^{52}$ But Anscombe wants us to resist this restrictive conception of responsibility. Just as a need for a transplant would not justify killing another person to harvest her organs, so too a person can be blamed for murdering someone, even if she does so because of a gun to her head.

${ }^{49}$ An important articulation of this alternative concept of consent appears in the Nuremberg Code, which states that voluntariness requires choices to be made 'without the intervention of any element of force, fraud, deceit, duress, over-reaching, or other ulterior form of constraint or coercion'. Indeed, some have criticised Anscombe on precisely the grounds that her concept of the voluntary extends to actions done under threat. For example, in the course of challenging Anscombe's concept of voluntariness John Hyman concludes that 'it is clear that coercion and voluntariness are opposed, where the patient of an act is concerned, because whether an act is voluntary on the part of the patient depends on whether it is done with her consent, and a sufficiently grave threat vitiates consent' (Action, Knowledge, and Will (Oxford: Oxford University Press, 2015), pp. 88-89). This occurs within a wider critique of philosophers who have neglected what Hyman argues is the essentially ethical character of the concept of voluntary action (ibid., pp. 76-77). However, as we argue below, Anscombe's own view at least by the 1960s was that to define something in terms of the voluntary is to bring it under an ethical concept, to appeal to notions of what agents can and ought to do and think. In this respect, then, Hyman's position does not present a meaningful contrast with Anscombe's. For discussion of Hyman's critique with reference to Anscombe's position in Intention, see John Schwenkler, Anscombe's Intention: A Guide (New York: Oxford Unversity Press, 2019), pp. 202-203.

50 'Sin', p. 127.

${ }^{51}$ Archive, Box 9, File 304, p. 2; and for Aristotle, see Nicomachean Ethics, Book III, Chapter 1.

52 Robert Nozick defends position like this in 'Coercion' (in Socratic Puzzles (Cambridge: Harvard University Press, 1997), at p. 38). 
Similarly, a Christian will hold that apostasy is sinful even when the alternative is certain martyrdom. This is not to deny that in some cases the presence of a threat might count as a sufficient excuse for acting in a way that would otherwise be sinful. For instance, if someone holds a gun to my head and tells me to take a watch while leaving the store, then I shouldn't be blamed if I do what they say. But that is not because we should not attribute this choice to my will. Rather, it is because we recognise my choice as an appropriate response to the circumstances I was in.

It should go without saying that when Anscombe says that voluntary actions are those that are attributable to an agent's will, she is not suggesting anything Cartesian. It is not as though we can look at two actions, find that only the second issued from a peculiar interior movement of the mind (a 'bare willing,' perhaps), and thus find the agent responsible for only the second act. ${ }^{53}$ Indeed, there will be times where 'the very existence of will ... may consist in nothing but some particular action itself' ${ }^{54}$ Rather, to attribute an action to an agent's will is simply to attribute the action to a person qua rational animal. That is, it is to represent the action as something for which the agent is responsible..$^{55}$

${ }^{53}$ For discussion of this sort of position, see Intention, $\S \S 19$ and 25; and 'Sin', pp. 129 and 137-8.

54 Archive, Box 9, File 304, p. 1

55 One needs to be careful using the word 'responsible' in discussing Anscombe's work. In much of her archival content she distinguishes between three levels of responsibility (e.g. Archive, Box 8, File 290, pp. 23-30; Box 8, File 292, pp. 5-17; and Box F5, File 509, pp. 115-135). She also articulates this distinction in her final draft of the paper 'Murder and the Morality of Euthanasia' in Geach and Gormally, eds., Human Life, Action, and Ethics: Essays by G. E. M. Anscombe (Exeter: Imprint Academic, 2005), 261-278; at pp. 261-262. On her view, there is a first level of responsibility that consists just in having one's physical body be a cause of an occurrence. Thus either I, or a boulder, could be the cause of an infant's death if dropped from a sufficient height. The second level of responsibility involves what she calls 'answerability', or being such that one may be called to account for what happened. This is only possible for rational agents who are able to justify or excuse their actions, but it does not entail blame or guilt, which she sees as arising only at a third level. In short, third level responsibility means that an act is attributable to the agent's will, while second level responsibility means that it is a candidate for such attribution, though it could be that the agent has a good excuse. For Anscombe, this concept of second level responsibility depends on that of responsibility at the third level. We could have the concept of guilt without any idea of excusing conditions, but we cannot have the idea of being in a position to require an excuse without having the concept of guilt. Anscombe thinks it is this third level of responsibility which grounds the concept of merit (in 
This definition makes it clear why what a person thinks has a bearing on whether she acts voluntarily in doing a certain thing. The claim not to have known that one was doing something is taken to provide at least prima facie grounds for withholding blame for that action. As we will discuss below, however, it is not in every case that ignorance of an action suffices to show that a person was not responsible for what she did. The real picture is considerably more complicated than that.

\section{Guilt and Sin}

The question 'When does ignorance excuse?' is central to both 'On Being in Good Faith' and 'The Two Kinds of Error in Action'. We can motivate this question by beginning with a simple case. If I give a peanut butter and jelly sandwich to a child for lunch after being told by his parents that the child has no known allergies, then I am not guilty of killing the child or otherwise responsible for his death, even by negligence, should the child undergo a deadly anaphylactic shock (assuming I do all in my power to save the child after he goes into anaphylaxis). This is the case even though giving peanut butter to a child with a severe peanut allergy has a good chance of resulting in the child's death. We can easily construct alternative cases where one murders a child by knowingly giving them a sandwich to induce anaphylaxis. However, in our original case I am not responsible for any wrongdoing.

Anscombe identifies two mistakes that can be prompted by this observation. First, noticing the way that ignorance exonerates in the example just discussed, one might conclude that a person cannot do something voluntarily if the person is ignorant of the fact she is doing this. Applied to the case just discussed, the thought would be that because I did not know I was

the context of praise or reward) as well as blame and sin. Here, we will use 'responsibility' to refer to the concept at this third level. 
killing the child in giving him the sandwich, I am not responsible for having killed him.

Similarly, one might continue, because I did not know I was doing anything wrong, therefore I am not guilty of any voluntary wrongdoing.

Yet this cannot be right. For surely not all ignorance excuses! Suppose, for example, that I knew that the child was severely allergic to peanuts but failed to understand that killing by peanut was murder, perhaps because I had the bizarre thought that this would be a natural death since peanuts are naturally a food. No one would think that this bit of ignorance constitutes an excuse for what I did. My ignorance about the nature of murder would not excuse me from the charge of it. This result is consonant with what we found in Part II. An act is not an act of murder if the agent did not know that they were killing someone, but it can still be an act of murder if the agent did not know that their action was properly classified as such.

This then suggests the second mistake Anscombe thinks we are prone to make. One might, considering these two cases together, conclude that classifying an action as voluntary is like classifying it as an act of theft. Voluntariness requires the agent to know the circumstantial facts of her action, but does not require the agent to know the classificatory facts. In the context of sin and guilt, the distinction between classificatory and circumstantial dependency maps directly onto the distinction between law and circumstance. And thus we seem to reach the doctrine that ignorance of circumstance excuses, but ignorance of law does not.

Anscombe has two reasons for rejecting this simple analysis of the relation between knowledge and voluntariness or responsibility. First, while she agrees that there are many cases in which ignorance of circumstances means that a person is not responsible for something she does, she argues that not all ignorance of circumstance has this effect. Suppose, for example, that I work at a summer camp, and during staff training they have a meeting about student safety and 
allergies. Thinking the meeting sounds boring, I skip it and so fail to learn that several children attending the camp have deadly peanut allergies, and as such we are forbidden from serving any peanut products. Having skipped the meeting, I, in ignorance, kill a child by serving peanut butter and jelly sandwiches to my class. Here, even though I am ignorant of the circumstantial fact that my action will endanger the child, it remains appropriate to hold me responsible for the child's death. That is because, as a camp counselor, I ought to have gone to the safety meeting. Anscombe puts this by saying that though in this case I was ignorant of the circumstances of my action, that ignorance itself was voluntary, in the sense of being attributable to my will.

In addition to arguing that we are sometimes blameworthy for ignorance of the circumstances of our action, Anscombe also rejects the claim that classificatory ignorance, or ignorance of law, is never an excusing condition. ${ }^{56} \mathrm{Her}$ clearest example of guiltless, and therefore exculpatory, ignorance of law comes in 'The Two Kinds of Error in Action', where asks us to imagine a 'public executioner who has private knowledge of a condemned man's innocence' that he is unable to use to publicly exonerate the man. ${ }^{57}$ Suppose that this executioner knows there has been a procedurally fair trial, and the man has been deemed guilty by a rightful legal authority properly empowered to kill by execution. To kill such a person would be to kill an innocent man, yet Anscombe thinks it is a difficult question whether executing the person, in such a case, is murder. As such, if the executioner 'forms a bona fide judgement that he can or should execute the man, and acts accordingly, then murder cannot be imputed to him' even if in fact our executioner does indeed commit an act of murder.

${ }^{56}$ As is so often the case, Anscombe draws here on ideas that she finds in St. Thomas Aquinas. On the difficulty of knowing the dictates of eternal law as applied to certain difficult cases, see Summa Theologiae, IaIIae, q. 93, a. 2, c, and q. 94, a. 4, c. And on the possibility of voluntary ignorance of the sort just discussed, see $S T$, IaIIae, q. 6, a. 8, c. In the last article Aquinas includes a third possibility that Anscombe does not mention, namely that a person's ignorance may be voluntary if it is the result of a desire not to know a certain thing.

${ }^{57}$ For this case see 'The Two Kinds of Error in Action', p. 7. 
In the case just considered, if the executioner is ignorant then his ignorance is not of circumstance, but of law. He knows every relevant fact, but mistakenly, and reasonably, errs in his practical reasoning. Now, Anscombe agrees with all the 'best writers' from Aristotle on, that 'where it was easy to know the law, then there is no possibility of exoneration' ${ }^{58}$ However, she does not think that this same analysis extends to the 'recondite parts of the law of nature; decisions about right and wrong involving remote and unobvious conclusions from the main outlines of the law'. ${ }^{59}$ Anscombe's case of the executioner differs from our second version of the peanut case, because a belief that killing children by peanut is not murder is not a belief one can come to faultlessly. One could not, in any real-life circumstances, be involuntarily ignorant of the fact that causing a child to die by allergic reaction is murderous, and so any such ignorance would be attributable to a failing of one's rational will. By contrast, the executioner could have come to his mistaken belief entirely faultlessly, and so could be guiltlessly ignorant of this recondite part of the moral law. ${ }^{60}$

This account allows us to vindicate the exculpatory role of ignorance, but without making room for the idea that strategic inculcation of ignorance is a possible way of keeping oneself guiltless. When ignorance excuses, this is because of the way it decouples an act from the agent's will. ${ }^{61}$ However, voluntary ignorance could not decouple an act from an agent's will because the

${ }^{58}$ Ibid. p.7

59 'On Being in Good Faith', p. 108.

60 To the extent that Anscombe has an argument for the claim that the execution case could involve involuntary ignorance, it seems to be that great Catholic theologians have, in good faith, disagreed about the case, and thus it is unreasonable to expect a less educated layperson to parse the moral law successfully in such conceptual extremities.

${ }^{61}$ A complete exploration of why ignorance decouples act from the will is beyond the scope of this paper. However, you can begin to see why if you accept Anscombe's view that it is through her practical knowledge that a human being acts, and so since ignorance compromises that knowledge, it compromises the capacity for willing to manifest in action. 
ignorance itself is now willful. ${ }^{62}$ Strategically inculcated ignorance cannot render a person guiltless for what otherwise would be wrongdoing, because strategically inculcated ignorance is ignorance that the agent herself is responsible for.

At this point, however, a concern about circularity arises. On Anscombe's view, acts are voluntary only if we either know or are voluntarily ignorant of the character of our actions. To say this is to employ the notion of the voluntary in our definition of voluntariness! Anscombe is well aware of this problem, and recognises that to make good on her account she will need to articulate a notion of the voluntary that can make sense of both voluntary action and voluntary ignorance. This, in turn, depends on an account of the nature of omissions, which in the end will yield the thesis that voluntary ignorance is omitting to know.

\section{Omissions}

In both 'On Being in Good Faith' and 'The Two Kinds of Error in Action', Anscombe begins her discussion of omissions by looking at what goes on when we attribute the sinking of a ship to a pilot. If a pilot steers a ship into an iceberg, then we would say the pilot sank the ship. But we would also blame the pilot for sinking the ship if at the time it hit an iceberg the pilot was supposed to be navigating the ship, yet was taking a nap as the ship went into dangerous waters. So some omissions, like the pilot's failure to navigate, are such that we attribute their consequences to the agent. And this seems to have something to do with the special role of the

\footnotetext{
${ }^{62}$ In an archival manuscript titled 'Moral Action Descriptions' Anscombe draws out this connection explicitly, noting that omissions are voluntary just in so far as they can be attributed to the will: 'Will, given the possibility of "Let it be so" and also of "Let it not be so" being as it were said to the possibility envisaged, is (again as it were) the actual saying of one or the other ... When what is in question is an omission there is likely no action which is (as it were) a saying "Let it be so". The behaviour of omission is voluntary however just because the behaver (sic) is or has been in a situation of possibility of making something accord with his will, the 'something' being the occurrence or non-occurrence of the act which he omitted to perform' (Archive, Box 9, File 304, typescript pp. 1-2).
} 
pilot vis-à-vis the safety of the ship. Perhaps, as a passenger on the ship, like the pilot I could have gone to the helm and begun navigating rather than taking my afternoon nap. Yet we do not attribute the sinking of the ship to me in the same way we attribute it to the pilot. To the question, 'Why did the ship sink?', the answer 'Because the pilot was not navigating' is a perfectly good reply, whereas 'Because the passengers were not navigating' is not. What is the difference at work here?

According to Anscombe, the operative difference is simply that it was the pilot's job to navigate the ship, which is just to say that the pilot ought to have been navigating at the time he was not. So one necessary condition for being a person who, by omission, sank the ship or caused it to sink is that one ought to have done the thing that one omitted to do. This is not the only condition, however. For example, suppose a saboteur has ruined the machinery of the helm, rendering the boat unnavigable. In such a situation, we would no longer say that the pilot sank the ship by failing to navigate, since while it is true that pilots ought to navigate their ships, in this case the pilot was unable to navigate. (This is not to say that the pilot wouldn't deserve censure for taking a nap while the ship was in dangerous waters, or for failing to notice that the ship's machinery had been ruined.) Similarly, Anscombe thinks that at least in one sense we would not attribute the sinking of the ship to a pilot who died of a heart attack while piloting, whereas we might still attribute the sinking of the ship to a pilot who committed suicide while on duty ${ }^{63}$ The difference is that in one case the pilot could still have navigated the ship, while in the

${ }^{63}$ We say 'in one sense' because Anscombe thinks we often will identify what is responsible for some event without speaking of moral responsibility (see 'On Being in Good Faith', p. 110). Thus, we might say 'a rope saved someone's life by breaking at a critical moment', not because the rope had an obligation to hold, and it was up to the rope whether it would hold. But just because 'ropes are meant to hold' and 'we could not have told that it must break just then'. It is in this sense of responsibility that we the pilot who died of a heart attack 'could after all be said to have lost the ship'. This broader notion of 'ought' and 'can' is discussed at length in many of Anscombe's unpublished writings. She glosses the 'ought' description as 'it was antecedently going to be done, or should have been so, or would have been according to some rule, or it would naturally or normally be expected to be. Or it was needed for some purpose in hand' (Archive, Box 7, File 256, p. 2). This is significant because it can explain how 
other they could not. The second necessary condition on sinking the ship by omitting to navigate it is that one could have done what one omitted to do. ${ }^{64}$

Anscombe uses these examples to argue that the failure to do something is voluntarythat is, it is an omission - if and only if one 'could and ought to' have done what one failed to do ${ }^{65}$ And she applies this account to the concept that worried us above, i.e. that of voluntary ignorance. On her account, to be voluntarily ignorant of something, pertaining either to circumstances or to the law, is simply for it to be the case that one one could and ought to have known that thing, which in fact one failed to know. ${ }^{66}$

\section{Turning To Ethics}

This chapter has explored how Anscombe's understanding of what is distinctive in the description of human action developed during the decade following the publication of Intention. It is generally understood that Anscombe concluded in 'Modern Moral Philosophy' that much of

omissions can sometimes be morally obligatory (even though in such a case clearly one ought not perform the action one is omitting to perform). Perhaps a king's chef should ruin the potatoes by failing to add salt in order to protest an unjust salt tax levied on the people. Because it is the chef's job to add salt, we can still classify this as an omission.

${ }^{64}$ In her archival materials Anscombe gives another case where an omission would not be blameworthy. She notes that often omissions are blameworthy 'but not when what is omitted is itself a great wrong' (Archive, Box 7, File 240, p. 1). This is significant, because it helps address a potential moral conflict. In a case where you must kill one to save another, Anscombe argues it is not injustice to let the latter die. The mere fact that I can kill someone by omitting to save them does not, therefore, give rise to a conflict in our duties not to kill. How does this fit in the schema? It is not just that the agent has no obligation to save the person-for after all, if another way to save the person presents itself you are obligated to take it. Nor is it just that the agent cannot save the person, as they can do this by killing the former. Rather, we need to see the two requirements in conjunction: it is not the case that the agent can and ought to save the person, since the only ways the agent can save the person involve doing things they ought not do. Anscombe thinks that distinctions of this sort are important to resist certain utilitarian conclusions (Archive, Box 7, File 256, pp. 8-12).

${ }^{65}$ The notion of what could be 'done' should be understood as broader than actions. For Anscombe thinks one can omit, not just actions, but omissions as well. Suppose I am supposed to type up a list of event attendees to add to our company's marketing listserv, but I am asked to omit currently employees of the company. If I copy down Barbara's email, not realizing she works in H.R., then I failed to omit her name (Archive, Box 7, File 256, p. 1). Similarly, as a chef I could fail to omit anchovies from the caesar salad recipe when preparing a dish for a vegetarian customer.

${ }^{66}$ Anscombe often uses the language of what is 'possible and necessary' instead of what one 'can and ought to' do. She also once uses the language of 'possible and reasonable' (Archive, Box 8, File 292, p. 5). 
moral reasoning was corrupted, not because of mistakes in values, but because of a corrupt and confused understanding of intentional action. Intention is then seen as her attempt to counteract that corruption.

What we have argued here, however, is that Anscombe saw this project as going well beyond the territory covered in Intention. Mistakes about the nature of intention and intentional action are only one part of the story. By resolving these mistakes we can come to identify a distinctive way in which humans, unlike other animals, are able to know what they are doing in acting. Because we can know what we do in acting, ways of acting are opened up to us that circumstantially depend on this agential self-knowledge. And because we can act in this distinctively self-knowing way, it is possible to attribute our actions not just to our bodies but to our rational wills. Finally, it is because humans, unlike other animals, can have their excellences and failures properly attributed to their wills that we are creatures susceptible to ethical descriptions like virtue and $\sin$.

It is thus worth emphasizing that what we have presented here is still firmly within the realm of philosophical psychology. This chapter has been an investigation of how the applicability of certain forms of action description depends on the agent's own thoughts and rational capacities. It remains, for all that we have argued, an open question which of those actions descriptions are descriptions of morally good or bad kinds of acts. For Anscombe, murder, because it involves an understanding of its own circumstantial requirements, essentially entails moral responsibility. But it remains a substantive philosophical question whether murder is always wrong, or if sometimes in murdering a person is instead responsible, and so praiseworthy, for having acted well. 


\section{Works Cited}

Anscombe, G.E.M.. 1958. "Pretending." Proceedings of the Aristotelian Society, Supplementary Volumes XXXII: 279-294.

Anscombe, G.E.M.. 1963, Repr. 2000. Intention, $2^{\text {nd }}$ ed. Cambridge: Harvard University Press.

Anscombe, G.E.M.. 1981a. "The Two Kinds of Error in Action." In Collected Philosophical Papers, Volume III: Ethics, Religion, and Politics, 3-9. Oxford: Basil Blackwell.

Anscombe, G.E.M.. 1981b. "On Promising and its Justice, and whether it need be respected in foro interno." In Collected Philosophical Papers, Volume III: Ethics, Religion, and Politics, 10-21. Oxford: Basil Blackwell.

Anscombe, G.E.M. 1981c. “On Brute Facts.” In Collected Philosophical Papers, Volume III: Ethics, Religion, and Politics, 22-25. Oxford: Basil Blackwell.

Anscombe, G.E.M.. 1981d. "Modern Moral Philosophy." In Collected Philosophical Papers, Volume III: Ethics, Religion, and Politics, 26-42. Oxford: Basil Blackwell.

Anscombe, G.E.M. 2005. "Murder and the Morality of Euthanasia." In Geach and Gormally, eds., Human Life, Action, and Ethics: Essays by G.E.M. Anscombe, 261-278. Exeter: Imprint Academic.

Anscombe, G.E.M. 2008a. "Authority in Morals." In Geach and Gormally, eds., Faith in a Hard Ground: Essays on Religion, Philosophy and Ethics by G.E.M. Anscombe, 92-100. Exeter: Imprint Academic.

Anscombe, G.E.M. 2008b. "On Being in Good Faith." In Geach and Gormally, eds., Faith in a Hard Ground: Essays on Religion, Philosophy and Ethics by G.E.M. Anscombe, 101-112. Exeter: Imprint Academic.

Anscombe, G.E.M. 2008c. "Sin: the McGivney lectures." In Geach and Gormally, eds., Faith in a Hard Ground: Essays on Religion, Philosophy and Ethics by G.E.M. Anscombe, 117156. Exeter: Imprint Academic.

Descartes, René. 1996. "Second Meditation." In Meditations on First Philosophy: With Selections from the Objections and Replies, 16-23, trans. John Cottingham. Cambridge: Cambridge University Press.

Frey, Jennifer, and Christopher Frey. 2017. "G.E.M. Anscombe on the Analogical Unity of Intention in Perception and Action." Analytic Philosophy 58, no. 3. 202-247.

Helton, Grace. 2018. "Visually Perceiving the Intentions of Others." The Philosophical Quarterly 68, no. 271: 243-264.

Hornsby, Jennifer. 2001. Simple Mindedness. Cambridge: Harvard University Press. Hyman, John. 2015. Action, Knowledge, and Will. Oxford: Oxford University Press. Nozick, Robert. 1997. “Coercion.” In Socratic Puzzles. Cambridge: Harvard University Press.

Schwenkler, John. 2019. Anscombe's Intention: A Guide. New York: Oxford University Press. Thompson, Michael. 2008. Life and Action. Cambridge: Harvard University Press.

Thompson, Michael. 2010. “Anscombe's Intention and Practical Knowledge.” In Ford, Hornsby, and Stoutland, eds., Essays on Anscombe's Intention, 198-210. Cambridge: Harvard University Press. 